九州大学学術情報リポジトリ

Kyushu University Institutional Repository

\title{
A Survey of Growth Stimulators in Natural Rubber Serum Powder for Bifidobacterium bifidum
}

Etoh, Shin-ichi

Laboratory of Microbial Technology, Department of Food Science and Technology, Faculty of Agriculture, Kyushu University

Sonomoto, Kenj i

Laboratory of Microbial Technology, Department of Food Science and Technology, Faculty of Agriculture, Kyushu University

Ishizaki, Ayaaki

Laboratory of Microbial Technology, Department of Food Science and Technology, Faculty of Agriculture, Kyushu University

https://doi.org/10.5109/24292

出版情報：九州大学大学院農学研究院紀要. 43 (3/4)，pp.451-460，1999-02. Kyushu University バージョン：

権利関係 : 


\title{
A Survey of Growth Stimulators in Natural Rubber Serum Powder for Bifidobacterium bifidum
}

\author{
Shin-ichi Etoh, Kenji Sonomoto and Ayaaki Ishizaki \\ Laboratory of Microbial Technology, Department of Fond Science and Technology, \\ Faculty of Agriculture, Kyushu University, 6-10-1, Hakozaki, Higashi-ku, \\ Fukuoka 812-8581, Japan \\ (Received October 28, 1398 and accepted November 6, 1998)
}

\begin{abstract}
Natural rubber serum powder, rich in crude protein and carbohydrates, had a strong growth-stimulating activity for Bifidobacterium bifidum, which was unable to grow in a fully synthetic medium, $\mathrm{B}_{1:}$ assay medium. Natural rubber serum powder was fractionated by intrafiltration (molecular weight cut off 1000 ). The active ultrafiltrate was furthermore concentrated and desalted with an adsorptive microconcentrator, which adsorbs virtually all amino acits and peptides. Through this purification stcp, it was found that the adsorbed fraction obtained could not exhibit a growlh-stimulating activity independently but acted complementarily with anmonium sulfate contaminated in the ultrafiltrate, Furthermore, ammonium sulfate could be substituted with other ammonium salts, anmonium chloride and ammonium nitrate. The adsorbed fraction was subsequently analyzed on reversed-phase high performance liquik chromatography, and the activities of the eluates were moasured on $B .2$ assay medinm supplemented with ammonium sulfate. Consequently, it was proved that several ingredients in the adsorbed fraction cnhanced the growth of $B$. bifidum.
\end{abstract}

\section{INTRODUCTION}

Bifidobacteria are gram-positive, saccharolytic, anaerobic bacteria that are major components of the human gastrointestinal tract. The most important benefits on the host health are inhibition or displacement of undesirable microorganisms, elimination of procarcinogens, immunomodulation, and vitamin production (Gibson and Wang, 1994; Kado-oka et al., 1991; Modler et al., 1990; Noda el al., 1994; Withelm et al., 1987). As a result, they are often used as food supplements and in milk fermentation (Ishibashi, 1990). However, biomass production is low because these microorganisms require a growth-stimulating factor, bifidogenic growth stimulator (BGS) which is usually absent even in fully synthetic media composed of sugars, vitamins, nuclejc and amino acids. Therefore, several investigations have been reported on a number of potential sources of BGSs. Poch and Bezkorovainy (1988) showed the availability of bovine casein digest and yeast extract, as BGSs in a fully synthetic medium similar to the well-known Norris medium (Poupard et al., 1973). Moreover, Ibrahim and Bezkorovainy (1994) investigated the growth-stimulating activity of various organic compounds for $B$. longum by using $B_{12}$ assay medium, which alone permitted only limited bifidobacterial growth. However, most of them are costly and/or have some other drawback. For example, B. bifidum cannot utilize many kinds of oligosaccharides, such as fructooligosaccharide (Hidaka, 1993) and soybean oligosaccharide (Masai, 1988), which are well known as BGSs. Except these oligosaccharides, there are a fow reports on completely identified BGSs to date (Mori et al., 1997). 
Natural rubber serum powder (NRSP) is a natural rubber waste, rich in crude protein and carbohydrates, produced during the manufacturing process of latex rubber (Ishizaki, 1989). Several attempts to utilize NRSP as a newly fermentable substrate have been carried out in our laboratory as means of reducing its polluting effect on the environment (Tripetchkul et al., 1992; Chinachoti et al., 1997). We have observed that NRSP has a strong growth-stimulating activity for a wide range of bifidobacteria of human origin (Ishizaki, 1995). In addition, Oiki et al. (1996a) investigated the effect of NRSP on $B$. bifidum in detail using bifidobacterium medium and/or the minimal medium without organic nutrient. NRSP showed synergistic effects with various organic nutrients in a similar manner to casein, which is composed of many kinds of peptides. However, both nutrients had different concentration-related cffects on the growth of B. bifidum (Oiki et al., 1996b). Further investigating into the nature of NRSP, the complexity of the experimental media appears to make it difficult to clearly understand the nutritional effects of NRSP on B. bifidum, and to distinguish whether the effect of NRSP is attributed to a simple nutritional source or BGS. Furthermore, we have observed a lower sensitivity of cells to the growth-stimulating activity of BGSs when partially purified BGSs from NRSP was added to bifidobacterium medium which alone could easily lead to much cell proliferation. To solve these problems, the use of a chemically defined medium mentioned above is necessary. In this paper, we attempted to prove the growth -stimulating effects of NRSP by using $\mathrm{B}_{12}$ assay medium, and to isolate the active ingredients from NRSP that act as BGSs.

\section{MATERIALS AND METHODS}

\section{Microorganism}

B. bifidum JCM 1254, of human origin, was purchased from the Japan Collection of Microorganisms, Wako.

\section{Natural rubber serum powder (NRSP)}

NRSP was provided by Nakanihon Air Service Co., Ltd. (Nagoya). NRSP used in this study was the spray-dried product of natural rubber serum imported from Malaysia. It was composed of many kinds of amino acids, peptides, inorganic salts and so on. The detailed composition of NRSP was described previously (Ishizaki, 1989).

\section{Bioassay}

The microorganism was grown in anaerobic jars (GasPak, BBL Microbiology Systems, Cockeysville, MD, U.S.A.) in thinglycolate (TGC) medium without dextrose (Difco Laboratories, Detroit, MI, U.S.A.) and stored at $5^{\circ} \mathrm{C}$. The stored culture was precultured in the bifidobacterium medium (Ishizaki, 1995) at $37^{\circ} \mathrm{C}$ for $24 \mathrm{~h}$. The culture broth was centrifuged at $8,000 \times \mathrm{g}$ for $10 \mathrm{~min}$. The precipitate cells were washed two times and suspended with sterile solution of $\mathrm{KCl}(1.08 \%)$. The basal medium used for a bioassay was $B_{12}$ assay medium (Difco). The assay medium $(3.6 \mathrm{ml}$ ) was mixed with $0.4 \mathrm{ml}$ of samples and then inoculated with $5 \%$ of the prepared inoculumn. The control contained $0.4 \mathrm{ml}$ of water instead of the samples. Culture was carried out under an anaerobic condition at $37^{\circ} \mathrm{C}$. The extent of growth was determined by measuring the absorbance at 
$562 \mathrm{~nm}\left(\mathrm{~A}_{562}\right)$ at various time intervals. The growth experiments were performed in duplicate or more each time, and resulting values were averaged in each experiment.

\section{Purification of BGSs}

NRSP was applied to ultrafiltration with a membrane of molecular weight cut off (MWCO) 1000 (Amicon, Inc., Beverly, MA, U.S.A.). The ultrafiltrate oblained was transferred into an adsorptive microconcentrator (MICROCON-SCX, Amicon) and centrifuged at $1,200 \times \mathrm{g}$ for $1 \mathrm{~min}$ to remove low-molecular-weight contaminants from the samples. The components adsorbed on the column were eluted with $1.4 \mathrm{~N} \mathrm{NH}_{4} \mathrm{OH} / \mathrm{MeOH}$ desorption reagent by centrifugation at $14,000 \times \mathrm{g}$ for $15 \mathrm{sec}$. The eluate was dried with Speed Vac Concentrator (Savant Instruments, Inc., Holbrook, NY, L.S.A.) and dissolved in water. The prepared samples were subjected to a reversed-phase high performance liquid chromatography (HPLC) on a DAISOIPAK SP-120-5-ODS-BP column (Daiso Co., Ltd., Osaka; $25 \mathrm{~cm} \times 4.6 \mathrm{~mm}$ inner diameter) and eluted with a linear $\mathrm{CH}_{3} \mathrm{CN}$ gradient $(5-40 \%, 35 \mathrm{~min})$ in water at a flow rate of $0.5 \mathrm{ml} / \mathrm{min}$, while monitoring the absorbance at $210 \mathrm{~nm}$. The isolated fractions were then collected and dried with Speed Vac Concentrator.

\section{RESULTS AND DISCLSSION}

\section{Effect of NRSP in $B_{12}$ assay medium}

Although $B$. bifidum could not be grown in $\mathrm{B}_{12}$ assay medium at all, the addition of $1 \%(w / v)$ NRSP to the medium remarkably enhanced its growth (Fig. 1). This result

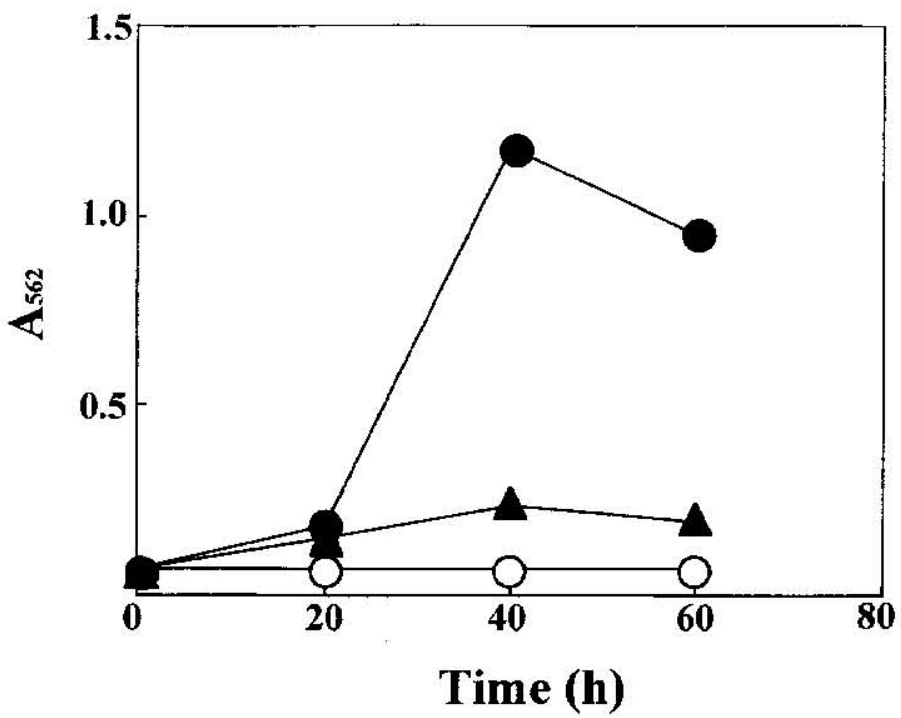

Fig. 1. Effects of NRSP and ammonium sulfate on Bifidobacterium bifidum JCM 1254 in $\mathrm{B}_{12}$ assay medium. $\mathrm{B}_{1:}$ assay medium (O) was supplemented with $10 \mathrm{~g} / \mathrm{NRSP}$ and $2.5 \mathrm{~g} / \mathrm{l}$ ammonium sulfate $(\boldsymbol{\Delta})$. 
indicates the higher sensitivity of cells to the growth-stimulating activity of NRSP on $\mathrm{B}_{12}$ assay medium, the cell growth being slower compared to it in the bifidobacterium medium. NRSP contains ammonium sulfate (Ishizaki, 1989), the concentration of which was found to be ca. 25\% (w/w-NRSP). Since ammonium sulfate is known to be one of the major nitrogen sources of bifidobacteria (Tanaka and Mutai, 1980), this inorganic salt in NRSP was considered to exhibit some of the growth-stimulating activity of NRSP as a contaminant. Actually, ammonium sulfate aided the growth of $B$. bifidum an a nutritional medium, which was inferior to the effect of NRSP (Oiki et al, 1996b). Therefore, the effect of ammonium sulfate at the concentration corresponding to that contained in NRSP on B. bifidum was assessed in this experiment. As shown in Fig. 1, the growth of the test strain was slightly affected by the addition of $0.25 \%$ ammonium sulfate to the medium. These results indicate that biologically active ingredients other than ammonium sulfate, namely BGSs, would probably be the main active principles of NRSP and that $B_{12}$ assay medium was useful for evaluating the growth-stimulating activity of BGSs. In the process of purifying the BGSs from NRSP, thus, the growth-stimulating activity was defined as the absorbance of $562 \mathrm{~nm}$ after cultivation for $40 \mathrm{~h}$.

\section{Partial purification of BGSs from NRSP}

As a first purification step, we performed fractionation of NRSP by using ultrafiltration (MWCO 1000) to estimate the molecular size of the BGSs in NRSP. As shown in Fig. 2, the ultrafiltrate obtained had an activity almost equal to that of untreated NRSP, but the retained fraction hardly showed any growth-stimulating effects. This suggested that a low-molecular-weight material less than 1000 Da would be responsible for the growth-stimulating activity of NRSP.

Adsorptive microconcentrator contains a strong cation exchange membrane which adsorbs virtually all amino acids and peptides. This device was used to concentrate peptides and to desalt the ultrafiltrate. The eluate containing ammonium sulfates and so on was not found to have any growth-stimulating activity. However, the adsorbed fraction obtained also did not entirely exhibit growth-stimulating effects, even when the concentration of the fraction in the medium was increased (Fig. 3). Thus, despite a lack of the growth-stimulating activity in ammonium sulfate (Fig. 1), the activity of the ultrafiltrate was completely lost by desalting. To solve this contradiction, we assumed that ammonium sulfate removed could be one of the key components for the expression of the activity of the adsorbed fraction. Figure 3 shows that the adsorbed fraction expressed a growth-stimulating activity for B. bifidum in a dose-dependent manner in the presence of $0.25 \%$ ammonium sulfate. This result revealed the presence of certain growth stimulators in the adsorbed fraction. The activity of the adsorbed fraction, which was supplemented with ammonium sulfate, at the concentration corresponding to that contained in the ultrafiltrate was a little lower than that of the ultrafiltrate itself (The former value was $0.55 \mathrm{in} \mathrm{Fig.} \mathrm{3,} \mathrm{and} \mathrm{the} \mathrm{latter} \mathrm{was} 0.92$ in Fig. 2). Thus, we established a successful bioassay system to isolate the desired BGSs by completely desalting the ultrafiltrate and then supplementing a small amount of ammonium sulfate to $\mathrm{B}_{12}$ assay medium.

To rapidly isolate the BGSs from NRSP, the adsorbed fraction was directly analyzed on reversed-phase HPLC. The chromatogram is shown in Fig. 4. The eluates were 
broadly fractionated into four fractions, and the growth-stimulating activity of each fraction was measured on $B_{12}$ assay medium supplemented with $0.25 \%$ ammonium sulfate. Consequently, each fraction except for fraction A showed a growth-stimulating activity which was unique to that fraction (Table). The activity of the mixture of all the HPLC fractions was nearly identical with that of the adsorbed fraction (data not shown). Since all the active fractions showed a positive ninhydrin-reaction test, the active ingredients in these fractions appeared to be amino acids and/or peptides. However, the addition of a mixture of 20 kinds of amino acids could not stimulate the growth of the test strain on $B_{1:}$ assay medium (data not shown). This indicates that the peptide structure of the substances could be solely responsible for their functional activity.

Some of growth stimulators for other microorganisms, for example, Klebsiella, Lactobacillus, have been isolated from proteinaceous compounds as a single compound (Berg et al., 1981; Zhao el al., 1996). However, in this study, composite growth factors existed in the adsorbed fraction. Interestingly, the high-molecular-weight fraction obtained by ultrafiltration also exhibited remarkable growth-stimulating effects when

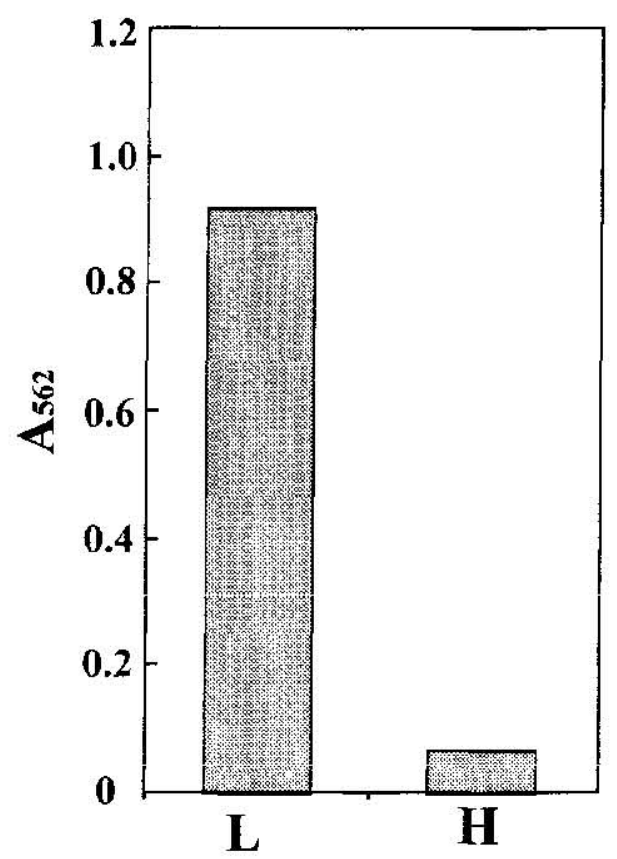

Fig. 2. Effects of uitrafiltrated NRSP on Bifidobacterium bifilum JCM 1254 in $\mathrm{B}_{1:}$ assay medium.

NRSP was fractionated into high-and low-molecular weight fractions $(\mathrm{H}$ and $\mathrm{L}$, respectively) by ultrafiltraction (MWCO 1000). Each fraction was added at the concentration corresponding to that contained in $10 \mathrm{~g} / \mathrm{l}$ NRSP. 


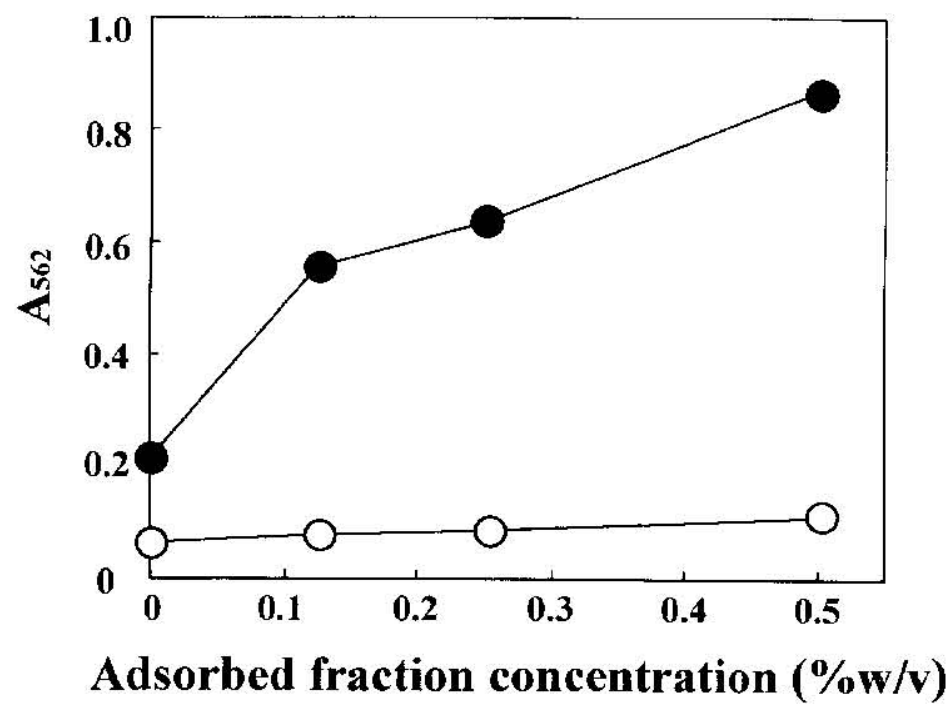

Fig. 3. Effects of concentrations of adsorbed fraction on Bifidobacterium bifidum JCM 1254.

Adsorbed fraction was obtained by treatment of the ultrafiltrate (MWCO 1000) of NRSP with adsorptive microconcentrator. $B_{1: \text { assay }}$ medium was supplemented with the adsorbed fraction in the presence of $2.5 \mathrm{~g} /$ ammonium sulfate $(\mathbf{)}$ ) and without ammonium sulfate $(\bigcirc)$. The concentration of the adsorbed fraction $(0.12 \%)$ corresponded to that contained in $10 \mathrm{~g} / \mathrm{N}$ NISP.

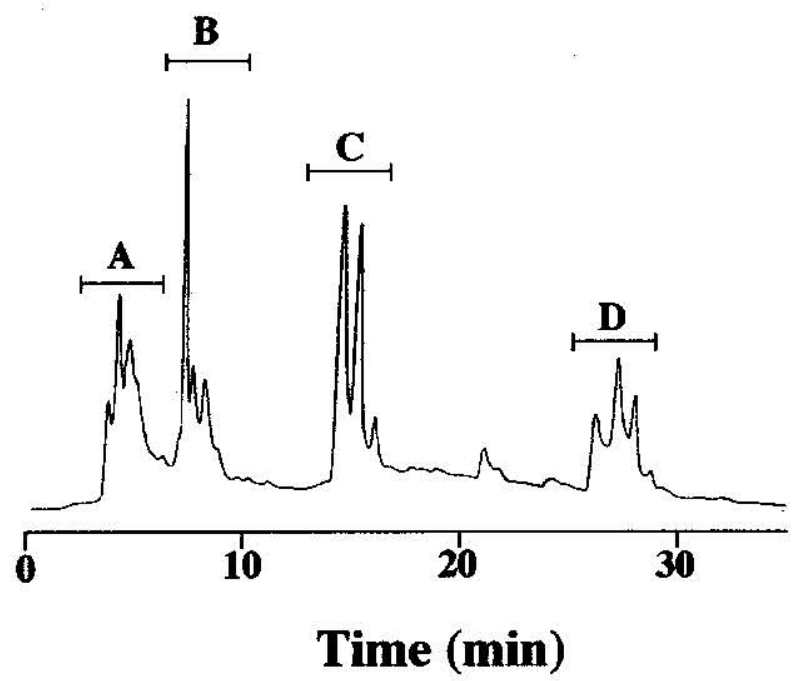

Fig. 4. Reversed-phase HPLC analysis of adsorbed fraction. The crude BGS from adsorptive microconcentrator was subjected to HPLC. 
ammonium salts also aided the expression of the activity of the BGSs although their complementary effects on the growth were different.

Oiki et al. (1996a) showed that NRSP' stimulated the growth of B. bifidum in a similar manner to cascin on the basis that both could be utilized not only as a growth stimulator but also as a source of nitrogen by $B$. bifidum on the minimal bifidobacterium medium. However, the complete removal of ammonium sulfate from NRSP revealed that the BGSs in NRSP could not act as a simple nitrogen supplier independently but express the activity through the complementary effects with inadvertently contaminated ammonium sulfate on a synthetic medium such as $\mathrm{B}_{22}$ assay medium. At present, we can not clearly understand the rolc of ammonium sulfate in the expression of the activity of the BGSs. It is considered that ammonium sulfate would support the expression of the activity of the BGSs cither directly or indirectly. Poch and Bezkorovainy (1991) have proposed a carrier for common metals, vitamins, or lipids, as one of the action mechanisms of $\kappa$-casein. On the other hand, Juillard et al. (1998) investigated the spccificity of milk peptide utilization by Lactococcus lactis. They also found that the

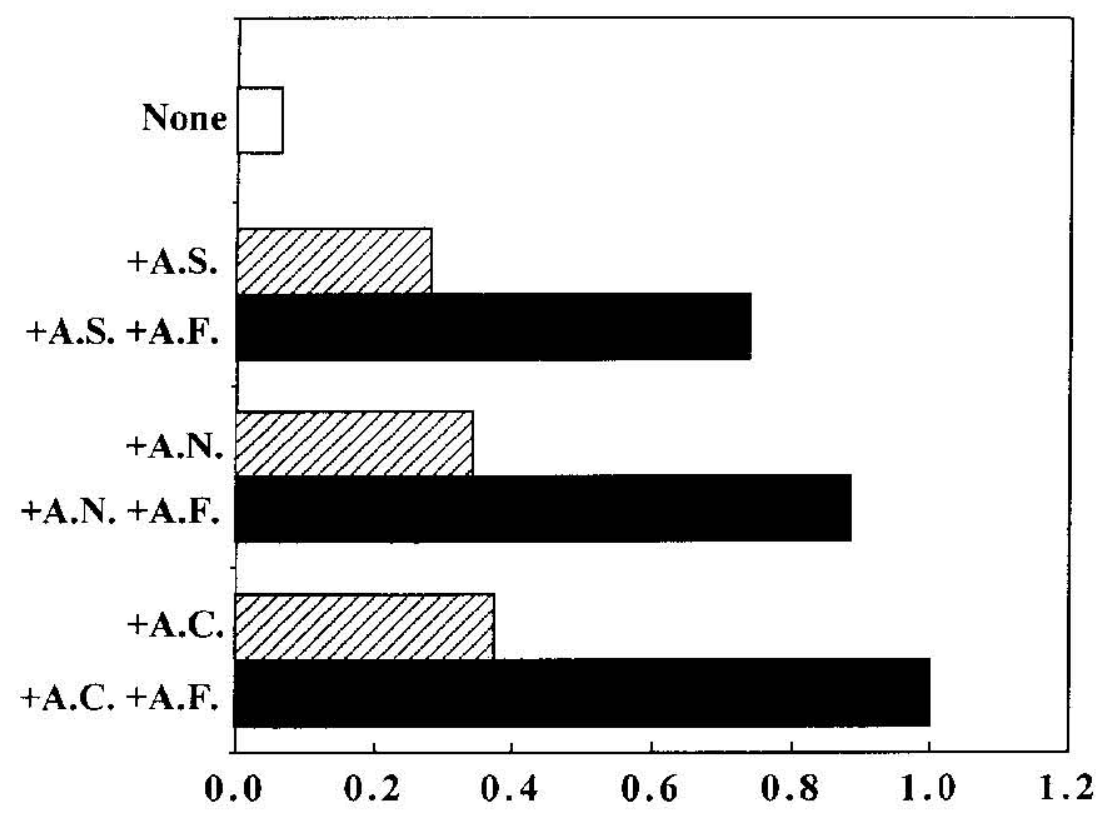

A562

Fig. 5. Effects of several ammonium salts on the expression of the activity of the BGSs. $\mathrm{B}_{\mathrm{k} 2}$ assay medium containing the indicated ammonium salts was supplemented with (black bars) and without (hatched bars) $0.24 \%(\mathrm{w} / \mathrm{v})$ adsorbed fracion (A.F.). Ammonium salls were added as follows: + A.S., $18.9 \mathrm{mM}$ armonium sulfate; + A.N. $37.8 \mathrm{mM}$ ammonium nitrate; + A.C., $37.8 \mathrm{mM}$ ammonium chloride. 
oligopeptide fraction in rullk required some essential amino acids contaminated for the expression of the growth-stimulating activity. Thus, it has been observed that peptide fraction cxpresses the activity together with additional nitrogen sources. Generally; some nutrients such as peptides and sugars are incorporated into a cell through various accumulated energy forms, such as proton motive force and ATP-driven force (Poolman, 1993). In our case, no cell-growth was observed in $\mathrm{B}_{12}$ assay medium alone (Fig. 1). This result indicates that intracellular metabolic flux would nol be fully activated. As a result, intracellular ATP production and formation of $\mathrm{pH}$ gradient between inner and outer mambrane did not occur. According to this hypothesis, the addition of ammonium sulfate, which was easily incorporated into a cell, triggered the cell growth as an additional nitrogen source, then the BGSs were subsequently utilized by the metabolically activated cells. Oiki et al. (1996b) actually found the metabolic activation of cells in the presence of NRSP. If there were nitrogen sources in the medium enough to grow cells even slightly, the BGSs might be effectively utilized by the test strain. Figure 5 demonstrates the expression of the activity of the BGSs by several ammonium salts which induced a little cell growth as nitrogen sources on $\mathrm{B}_{1:}$ assay medium. Especially, ammonium chloride exhibited a complementary effect more remarkably than other ammonium salts. The addition of ammonium chloride instead of ammonium sulfate to $B_{12}$ assay medium would lead to the establishment of a more excellent bioassay system for the further purification of the BGSs. At the industrial level, it is expected that a higher cell density culture should be done by the combination of the BGSs derived from NRSP with relatively cheap ammonium salts instead of expensive organic nitrogen sources. Nlthough the sludies on the uplake of sugars by Bifidobacterium have been reported by several investigators (Degnan and Macfarlane, 1993; Krzewinski et al., 1996, 1997), no publications on the peptide transport system are available. It is true that the BGSs would cxhibit a higher activity owing to the peptide structure, but the extent of energy demand for the uptake of the peptides might characterize the limited bifidobacterial growth compared to other microorganisms.

Furthermore, the peptide content in the medium used has been found to affect the regulation of proteolytic activity in Lactococcus lactis (Meijer et al., 1996). On the other hand, it has been reported that Bifidobacterium utilizes peptides produced by the proteinase of lactic acid bacteria, which is employed as a mixed starter in milk, due to its relatively low proteolytic activily (Tamine et al., 1995). In this view point, the relationship belween proteolytic activity of Bifidobacterium and the content of nitrogen sources in a medium seems to be intcresting. 'Thus, the presence of nitrogen sources in a medium could play a significant role in the process of the utilization of peptides in these microorganisms.

\section{REFERENCES}

Berg, R. W., W. E. Sandine and A. W. Anderson 1981 Identification of a growth stimulator for Lactobacillus sanfrancisco. Appl. Enwiron Microbiol., 42: 786-788

Chinachoti, N., H. Matsusaki, K. Sonomoto and A. Ishizaki 1997 Ltilization of xylose as an alternative carbon source for nisin 'Z production by Lactococous lactis IO-1. J. Fac. Agr., Kinushu Univ., 42: $171-181$

Degndn, B. A. and G. T. Macfarlane 1993 Transport and metabolism of glucose and arabinose in Bifidobacterium breve. Arch. Microbiol, 160: 144-151 
Gibson, G. R., and X. Wang 1994 Regulatory effects of bifidobacteria on the growth of other colonic: bacteria. J. Appl. Bacteriol, 77: 412-420

Hidaka, H. 1993 Functional sugar to improve human health, fructooligosaccharide. Gendai Kagctkpt, 268: 64-68 (In Japanese)

lbrahim, S. A and A. Bezkorovairy 1994 Growth promoting factors for Bifidobacterizm longum. J. Food Sici., 59: 189-191

Ishibashi, N. 1990 Application of Bifidobacterium for yogurt production. Biseibutsu, 6: 66-73 (in Japarnese)

Ishizaki, A. 1989 Ltilization of ratural rubber waste as medium ingredients for fermentation process. Microb. Litiliz Renewable Res., 6: $235-241$

Ishizaki, A. 1995 Natural rubber serum which contains a special growth promoter for Bifidobacteriurn. Biosci. Biolech. Biochem., 59: 1150-1151

duillard, V., A. Guillot, D. L. Bars and J-C. Gripon 1998 specificity of milk peptide utilization by Lactococcus lactis. Appl. Fitwiron Microbiol., 64: 1230-1236

Kado-oka, Y., S. Fujiwara and T. Hirota 1991 Effects of hifidobacteria cells on mitogenic responsc of splenocytes and several functions of phagocytes. Mitchwissenschajt, 46:626-6330

Krzewinski, F., C. Brassart, F. Gavini and S. Bouquelet 1996 Characterization of the lactose transport system in the strain Bifidobacterium bifidum DSM 20082. Curr Microbiol, 32: 301-307

Krzewinski, F., C. Brassart, F. Gavini and S. Bouquele 1997 Glucose and galactose transport in Bifidobacterium bifidum ISSM 20082. Curr. Microbiol., 35: 175-179

Masai, T. 1988 (haracteristies and application of soy-bean oligosaccharide. Syokuhin to Kagaku, 30: 98-103

Matteuzzi, D., F. Crociani and O. Entaldi 1978 Amino acids produced by bifidobacteria and some clostridia. Ann Microbiol., 129B: 175-181

Meijer, W., J. D. Marugg and J. Hugenholtz 1996 Regulation of proteolytic enzyme activity in Lactococus lactis. Appl. Enairon. Microbiol., 62: 156-161

Modler, H. W., R. C. McKellar and M. Yaguchi 1990 Bifidobacteria and bifidogenic factors. Cart. Inst. Food Sci. Techrol. J., 23: $29-41$

Mori, H., Y. Sato, N. Taketomo, T. Kamiyama, Y. Yoshiyama, S. Meguro, H. Salo and T. Karteko 1997 Isolation and structural identification of bifidogenic growth stimulator produced by Propionitacterium freudenreichit. J. Dairy Sei., 80: 1959-1964

Noda, H., N. Akasaka and M. Ohsugi 1994 Biotin production by bifictobacteria. J. Nutr. Sci. Vitaminol., 40: $181-188$

Oiki, H., K. Sonomoto and A. Ishizaki $1996 \mathrm{a}$ Stimulation by natural rubber serum powiter of the growth of Bifidobnclerium bifidum. J. Fac. Agr, Kyustu Liniv., 40: 271-277

Oiki, H., K. Sonomoto and A. Ishizaki $1996 \mathrm{~b}$ Growth-stimulating effects of natural rubber serum on Bifidobacterium bifidum. J. Ferment. Bioeng., 82: 165-167

lock, M. and A. Bezkorovairy 1988 Growth-enhancing supplements for various specjes of the genus Bifidobucierinem. Dairy Sci, 71: 3214-3221

Poch, M. and A. Bezkorovainy 1991 Bovine milk $\kappa$-casein tryjusin digest is a growth enhancer for the genus Bifidobacteriam. J. Agric. Food Chem., 39: 73-77

Poolman, B. 1993 Energy transduction in lactic acid bacteria. FEMS Microbiol Ren., 12: 125-148

Poupard, .J. A., I. Husain and R. F. Norris 1973 Biology of the bifidobacteria. Bacteriol. Rev., 37. $136-165$

Tamine, A. Y., V. M. E. Marshall and R. K. Robinson 1995 Microbiological and technological aspects of milks fermented by bifidobacteria. I. Dairy Res., 62: 151-187

Tanaka, R. and M. Mutai 1980 Improved medium for selective isolation and enumeration of Bifidobacterium Appl Environ. Microbiol., 40: 866-869

Tripetchkul, S., M. Tonokawa and A. Ishizaki 1992 Ethanol production by Zymomonas mobilis using natural rubber waste as a nutritional source. J. Ferment. Bioeng., 74: 384-388

Wilhelm, H. P., D. T. Lec and J. E. Rosenblatt 1987 Bacterial interferance by anacrobic species isolated from humar feces. Eur. J. Clin. Microbiol., 6: 266-270

Zhao, Q. Y., J. M. Piot, V. Gautier and G. Cottenceau 1996 Isolation and characterization of a bacterial growth-stimulating peptide from a peptic bovine hemoglobin hydrolysate. Appl. Microbiol. Biotechnol., 45: 778-784 